\title{
La actuación de la Inspección de Trabajo y Seguridad Social en relación con las personas con discapacidad 1
}

\author{
The action of the Labor and Social Security Inspection in relation to \\ people with disabilities
}

\begin{abstract}
Resumen
El objeto del presente artículo es el análisis de la actuación de la Inspección de Trabajo y de Seguridad Social en relación con las personas con discapacidad y, específicamente, el impacto de la misma tanto para el cumplimiento de la cuota de reserva de trabajadores con discapacidad en empresas de 50 o más trabajadores como, en general, para el incremento de la inclusión laboral del colectivo. La Inspección está realizando desde hace tres lustros una campaña específica de control de esta obligación legal. Se analizan los datos que publicita esta institución en sus memorias anuales y se proponen algunas mejoras. Los resultados demuestran que esta intervención administrativa ha sido muy interesante para aumentar la inclusión laboral del colectivo, aunque parece que hemos llegado a un tope, por lo que se propone la necesidad de un cambio de paradigma y la introducción de nuevas medidas de políticas activas de empleo.
\end{abstract}

\section{Palabras clave}

Empleo, personas con discapacidad, cuota de reserva, Inspección de Trabajo y Seguridad Social, paradigma, tasa de empleo, tasa de actividad, desempleo.

\begin{abstract}
The purpose of this article is the analysis of the action of the Labor and Social Security Inspection in relation to people with disabilities and, specifically, the impact for the compliance of the reservation free of workers with disabilities in companies with 50 or more workers as, in general, to increase the labor inclusion of the group. The Inspection has been carrying out a specific campaign to control this legal obligation for fifteen years at least. The data published by this institution in its annual reports is analyzed and some improvements are proposed. The results show that this administrative intervention has been very interesting to increase the labor inclusion of the group, although it seems that the top has been reached. For this reason, a paradigm shift and the introduction of new active employment policy measures are proposed.
\end{abstract}

\section{Keywords}

Employment, people with disabilities, reservation fee, Labor and Social Security Inspection, paradigm, employment rate, activity rate, unemployment.

1. El texto recoge la ponencia presentada con el mismo título en el Congreso de la Red Española de Política Social, en la mesa "Discapacidad, capacitismo y políticas sociales", celebrado de forma híbrida, presencial en Bilbao y virtual, del 15 al 17 de marzo de 2021.

\section{Carlos de Fuentes García- Romero de Tejada <carlosdf@ucm.es>}

Universidad Complutense de Madrid. España

\section{Segundo Valmorisco Pizarro} <svalmori@ucm.es>

Universidad Complutense de Madrid. España

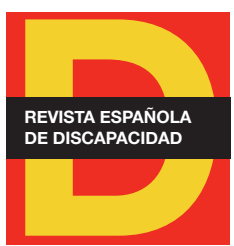

Para citar:

de Fuentes, C. y Valmorisco, S. (2021). La actuación de la Inspección de Trabajo y Seguridad Social en relación con las personas con discapacidad. Revista Española de Discapacidad, 9(2), pp. 7-22.

Doi: <https://doi.org/10.5569/23405104.09.02.01>

Fecha de recepción: 18-03-2021 Fecha de aceptación: 22-10-2021 


\section{Introducción: la necesidad de la actuación de la Inspección de Trabajo y de la Seguridad Social para la efectividad del derecho al trabajo de las personas con discapacidad}

El objeto del presente artículo es el análisis de la actuación de la Inspección de Trabajo y de Seguridad Social (en adelante, ITSS) con relación a las personas con discapacidad y, específicamente, el impacto de la misma tanto para el cumplimiento de la cuota de reserva del $2 \%$ de trabajadores con discapacidad en empresas de 50 o más trabajadores, regulada en el art. 42 del Real Decreto Legislativo 1/2013 por el que se aprueba el Texto Refundido de la Ley General de derechos de las personas con discapacidad y de su inclusión social como, en general, para el incremento de la inclusión laboral del colectivo.

En la legislación laboral y de seguridad social es necesaria la existencia de una intervención administrativa para controlar su cumplimiento y, en definitiva, para lograr su efectividad (Monereo, 2016, p. 242). "Las políticas públicas resultan imprescindibles para que los derechos se hagan realidad", en especial la política presupuestaria y la labor inspectora (Mora y Cabra de Luna, 2016, p. 80). En la normativa del Derecho social es más frecuente que se reconozca un derecho a que se pongan los medios para que éste sea efectivo. No obstante, "la imposibilidad del ejercicio de los derechos no es cosa distinta, en sus efectos, a la ablación llana y lisa de su titularidad" (Casas, 2007, p. 43). Por ello, la adopción de medidas administrativas y financieras es el complemento indispensable de la previsión de los derechos sociales para que sean una realidad (García, 2004, p. 283).

Esta situación ocurre, por supuesto, en el Derecho de las personas con discapacidad en donde "[l]as Leyes que se aprueban por estos dominios son, lamentablemente, las más de las veces, de la familia de las llamadas leyes manifiesto" cuya característica más expresiva es la de ser "una simple proclama política, incorporada a los programas por necesidades electorales (...), aprobadas sin ninguna intención de ejecutarlas" (Muñoz, 1996, p. XVII). De ahí que la actividad fiscalizadora de la ITSS resulte determinante para lograr la efectividad real de la profusa legislación, establecida desde hace ya cincuenta años -y cuyo máximo colofón es la Convención de Naciones Unidas sobre los Derechos de las personas con discapacidad de 2006-, para la inclusión social de este colectivo. De hecho, el protagonismo de la ITSS para alcanzar el cumplimiento efectivo de esta parte de la legislación social ha cogido fuerza en los últimos años y, por ello, entendemos que es buen momento de conocer los resultados de esta práctica, objetivo del presente trabajo.

\section{Las infracciones y sanciones en el orden social específicas para el trabajo de las personas con discapacidad}

La ITSS, como es conocido, es un órgano de la administración cuya misión fundamental es la vigilancia del cumplimiento de las normas del orden social. En la Ley de Infracciones y Sanciones del Orden Social (cuyo vigente Texto Refundido fue aprobado por el Real Decreto Legislativo 5/2000, de 4 de agosto; en adelante, LISOS) se recoge el elenco de incumplimientos que pueden llevar a cabo las empresas, las personas trabajadoras y, en menor medida, otros sujetos que intervienen en las relaciones laborales, así como los correctivos que pueden ser impuestos cuando se comprueba el quebrantamiento de una norma, como en lo que interesa para este estudio, el art. 42 de la Ley General de derechos de las personas con discapacidad. 
Vamos a analizar en primer término cuáles son las directrices específicas establecidas en la LISOS sobre las personas con discapacidad, quedando aparte las posibles infracciones por incumplimientos de cotización, relacionados algunos con los apoyos económicos a la contratación del colectivo. Las infracciones y sanciones recogidas en esta ley que versan sobre personas con discapacidad son las siguientes:

A. Se establece un posible sujeto exclusivo de incumplimientos en materia de la legislación de personas con discapacidad. Además de las personas, físicas o jurídicas, que ejerzan de empleador en la relación laboral, se establece que podrán ser sujeto infractor las fundaciones y asociaciones de utilidad pública beneficiarias de donaciones y acciones de patrocinio para el desarrollo de actividades de inserción y de creación de empleo de personas con discapacidad, como medida alternativa al cumplimiento de la obligación de la cuota de reserva a favor de este colectivo (art. 2.14 LISOS).

B. Se determinan las siguientes infracciones en relación con las personas con discapacidad:

a. Infracciones muy graves dentro del ámbito de las relaciones laborales, se establecen en el art. 8 LISOS:

i. Discriminación, directa o indirecta, a las personas con discapacidad (apartado 12).

ii. Acoso entre otras razones, por razón de discapacidad (apartado 13 bis).

b. Infracciones en materia de empleo y contratación:

i. Una falta con la calificación de grave:

1. El incumplimiento en materia de integración laboral de personas con discapacidad de la obligación legal de reserva de puestos de trabajo para personas con discapacidad, o de la aplicación de sus medidas alternativas de carácter excepcional (art. 15.3 LISOS). La redacción de este artículo "resulta en líneas generales correcta desde el punto de vista de la tipificación, y no presenta problemas en la mayoría de las actuaciones inspectoras, puesto que la referencia a la obligación incumplida es precisa y sin recursos indebidos a conceptos indeterminados" (Pérez, 2015, p. 472). Ahora bien, se ha solicitado (Pérez, 2015, pp. 472-473) que podría modificarse para incluir las posibles inobservancias de obligaciones de reserva de empleo para personas con discapacidad establecidas en los convenios colectivos. En efecto, la expresión incumplimiento de la "obligación legal" no deja espacio a que puedan sancionarse por la ITSS actuaciones empresariales que no cumplan con las posibles directrices que pudieran devenir de una norma convencional y, por ello, sería interesante su modificación en este sentido.

ii. Dos infracciones muy graves:

1. Solicitar datos de carácter personal en los procesos de selección, entre ellos relativos a la discapacidad, que constituyan discriminaciones para el acceso al empleo [art. 16.1.c) LISOS].

2. La aplicación indebida o la no aplicación a los fines legalmente previstos de las donaciones y acciones de patrocinio recibidas de las empresas, por parte de las fundaciones y asociaciones de utilidad pública, como medida alternativa al cumplimiento de la obligación de reserva de empleo a favor de las personas con discapacidad [art. 16.1.g) LISOS].

C. Para el caso de que una empresa (o fundación o asociación de utilidad pública) cometa alguna de los ilícitos anteriormente descritos se instauran las siguientes sanciones: 
a. Económicas:

i. Las leves, en su grado mínimo, con multas de 70 a 150 euros; en su grado medio, de 151 a 370 euros; y en su grado máximo, de 371 a 750 euros.

ii. Las graves con multa, en su grado mínimo, de 751 a 1.500 euros, en su grado medio de 1.501 a 3.750 euros; y en su grado máximo de 3.751 a 7.500 euros.

iii. Las muy graves con multa, en su grado mínimo, de 7.501 a 30.000 euros; en su grado medio de 30.001 a 120.005 euros; y en su grado máximo de 120.006 euros a 225.018 euros.

iv. Hay que tener en cuenta que para la infracción relativa al incumplimiento de la cuota de reserva (art. 15.3 LISOS) "la sanción se impondrá en su grado máximo cuando, en los dos años anteriores a la fecha de la comisión de la infracción, el sujeto responsable ya hubiere sido sancionado en firme por incumplimiento de la obligación legal de reserva de puestos de trabajo para personas con discapacidad o de la aplicación de sus medidas alternativas de carácter excepcional” (art. 39.2, último párrafo LISOS). En este sentido, se amplía el período de referencia para la apreciación de la reincidencia, que con carácter general es de un año.

b. Sanciones accesorias (art. 46.1 LISOS): si una empresa u organización comete una infracción, además de la multa económica, se le puede castigar con la:

i. Pérdida automática, y proporcional al número de trabajadores afectados por la infracción, de las ayudas, bonificaciones y, en general, beneficios a la contratación, con efectos desde la fecha en que se cometió la infracción.

ii. Posibilidad de que la pérdida establecida en el apartado anterior se mantenga por período de dos años.

c. Responsabilidades empresariales específicas (art. 46 bis, 1):

i. Se establecen unas sanciones añadidas, de pérdida de incentivos y ayudas a la contratación, desde la fecha de la sanción, que se puede incrementar hasta un plazo entre seis meses y dos años.

Por tanto, teniendo en cuenta todo lo anterior, de acuerdo a lo que ahora nos interesa, para la obligación legal de la cuota de reserva para personas con discapacidad se establece una infracción grave (art. 15.3 LISOS), a la que se le anuda una sanción económica [entre 750 y $7.500 €$, art. 40.1.b) LISOS]. Dicha sanción se impondrá en su grado máximo cuando, en los dos años anteriores a la fecha de la comisión de la infracción, el sujeto responsable ya hubiere sido sancionado en firme por este mismo motivo (art. 39.2, último párrafo LISOS). Además, el sujeto infractor perderá automáticamente las ayudas o bonificaciones a la contratación, en proporción al número de trabajadores afectados por la infracción, pudiendo ampliarse hasta un período de dos años (art. 46.1 LISOS).

Se ha valorado por la doctrina (Pérez, 2015, pp. 475-476) la conveniencia de que la calificación de la infracción debería pasar de grave a muy grave pues actualmente, "el efecto disuasorio de las actuales sanciones (...) resulta claramente insuficiente". Además, se propone que se puedan imponer tantas sanciones como el número de trabajadores que se han dejado de contratar y no como ocurre en la actualidad, que el incumplimiento de la cuota de reserva es considerado una única infracción sea cual fuere el número de trabajadores afectados. 
3. Análisis del Criterio técnico 98/2016 de la Inspección de Trabajo y de la Seguridad Social

Aunque es suficientemente conocido dado que lleva varios años en la práctica de la Inspección, consideramos que es pertinente explicar sucintamente el criterio técnico que utiliza esta institución para el seguimiento y verificación del cumplimiento de la obligación legal de la cuota de reserva para personas con discapacidad.

Debido a las dudas que revestía la aplicación práctica del régimen jurídico legal de esta institución en empresas de cincuenta o más trabajadores, la Dirección de la ITSS determinó la elaboración del Criterio técnico 98/2016 para unificar las diversas posiciones o razonamientos existentes sobre la materia. Se trata de la herramienta fundamental en la actuación inspectora en este asunto. Las claves del citado criterio (Fernández, 2017; Fundación SERES, 2018) nos ayudarán a conocer esta obligación legal empresarial. Son las siguientes:

A. La cuota de reserva es una obligación legal para todas las empresas (públicas o privadas) de cincuenta o más trabajadores. Se incluyen también las administraciones públicas y otras instituciones de carácter público (universidades, fundaciones del sector público, etc.), que son empleadores a los efectos del art. 1.2 del Estatuto de los Trabajadores, para quien rige la normativa del empleo público según la cual (artículo 59 del Estatuto Básico del Empleado Público) se establece que en las ofertas de empleo público se reservará un cupo no inferior al siete por ciento de las vacantes para ser cubiertas entre personas con discapacidad, siempre que superen los procesos selectivos y acrediten tanto su discapacidad como la compatibilidad con el desempeño de las tareas, de modo que progresivamente se alcance el dos por ciento de los efectivos totales en cada Administración pública (Pérez, 2012, p. 146). Debe entenderse en todo caso que lo que esta norma obliga a las empresas y administraciones públicas no es la contratación de personas con discapacidad sino la reserva de un determinado número de vacantes para el colectivo, al regir los principios de igualdad, mérito y capacidad en el acceso al empleo público.

B. El objetivo de la medida es la contratación de personas que tengan el reconocimiento administrativo del certificado de discapacidad igual o superior al $33 \%$.

C. La unidad de referencia del cálculo es la empresa (cada CIF), no el centro de trabajo ni el grupo de empresas.

D. El período de referencia son los doce meses inmediatamente anteriores. Por tanto, es un tema que puede fluctuar y, al no ser estático, exige al empresario ser previsor para no verse sorprendido por un incumplimiento en cualquier momento.

E. El empleador con 50 o más trabajadores debe contabilizar su plantilla de referencia y, a partir de ahí, debe calcular el número de empleados con discapacidad que debe tener mínimo en su plantilla. En este recuento puede contar, incluso, con los empleados con discapacidad de la empresa de trabajo temporal que trabajan para su organización.

F. Para calcular la plantilla de referencia deben contabilizarse todos los trabajadores, bien estén contratados a tiempo completo, bien parcial, pero hay diversas reglas según su modalidad contractual:

a. Los empleados con contrato indefinido y los que tengan contrato temporal que hayan trabajado los doce meses del período de referencia, cuentan uno. 
b. En relación con los empleados con contrato temporal el funcionamiento es el siguiente: se tienen que sumar todos los días de los contratos de todos los empleados y, a continuación, debe realizarse la siguiente operación; por cada 200 días trabajados, se cuenta un trabajador. Si hay decimales, se redondea por exceso. En todo caso, existe el límite máximo del número de trabajadores con contrato temporal que han trabajado en la empresa en el período de referencia.

G. Una vez contabilizada la plantilla de referencia, se debe calcular qué número de trabajadores con discapacidad debe contratarse, con un simple cálculo del $2 \%$ (o del $7 \%$ para las administraciones públicas a quien se aplica el art. 59 del Estatuto Básico del Empleado Público antes estudiado).

En el caso de que la cuota obtenida tenga números decimales, la normativa de referencia no aclara si se debe redondear por exceso o si, por el contrario, los decimales han de desecharse. El Criterio técnico 98/2016 de la ITSS, no obstante, aboga por una interpretación finalista de la norma; parece que la intención del legislador ha sido la de establecer un redondeo a la baja, y que no existe obligación de contratar a un trabajador con discapacidad más hasta que no se alcance el siguiente número entero. Por tanto, de 50 a 99 (1 trabajador), de 100 a 149 (2 trabajadores), etc. No obstante, en alguna comunidad autónoma como Cataluña se ha establecido el sistema de redondeo al alza a partir de 0,5 para calcular cuantas personas con discapacidad necesita una empresa para alcanzar el $2 \%$ (art. 3.3 del Decreto 86/2015, de 2 de junio).

La empresa es posible que pueda quedar exenta de esta obligación de reserva a favor de personas con discapacidad, de forma parcial o total, por aplicación de acuerdos recogidos en la negociación colectiva sectorial de ámbito estatal y, en su defecto, de ámbito inferior, a tenor de lo dispuesto en el art. 83.2 del Estatuto de los Trabajadores. Asimismo, también está previsto que la empresa pudiera solicitar a la administración la posibilidad de que se le concediera la excepcionalidad de tener que cumplir con esta obligación legal. Estas posibilidades no estaban previstas inicialmente por la normativa legal (art. 38 de la Ley de Integración Social de personas con discapacidad de 1982) pero se introdujeron por la Ley 66/1997 (disposición adicional 39) y en ambas se exige que se apliquen las medidas alternativas que están determinadas y desarrolladas en el Real Decreto 364/2005, de 8 de abril. En definitiva, con estas excepciones a la regla se permite a la empresa cubrir la cuota que le falta con la contratación de una medida alternativa (comprar bienes o servicios a centros especiales de empleo o trabajadores autónomos con discapacidad o bien donar a una entidad cuya finalidad sea la inclusión laboral del colectivo).

La excepcionalidad puede venir determinada, bien por la imposibilidad de contratación de trabajadores con discapacidad por parte de la empresa, que debe estar justificada en razones técnicas, económicas, organizativas o productivas, o bien por la imposibilidad por parte de los servicios públicos de empleo de atender las ofertas de empleo para contratar a trabajadores con discapacidad presentadas por la empresa. Por tanto, la empresa debe demostrar bien las razones de su organización que le impiden contratar personal con discapacidad, bien que no existen candidatos/as con discapacidad que cumplan los requerimientos de las vacantes de su entidad. Para ello, cuando tenga que cubrir una posición en la empresa, la empresa está obligada a solicitar a la oficina de empleo que le remita Curriculum Vitae de las personas con discapacidad inscritas en desempleo. Si logra verificar que no existen candidaturas acordes para la organización, la administración le podrá certificar temporalmente, y de manera excepcional, que puede cumplir la obligación de la cuota de discapacidad con las antes indicadas medidas alternativas.

La competencia para resolver este trámite la tiene asignada el Servicio Público de Empleo, bien estatal o de comunidad autónoma, en función del territorio en el que esté radicada la empresa. Será el de la 
comunidad autónoma cuando al menos el 85 por 100 de la plantilla total de la empresa radique en el ámbito territorial de dicha comunidad.

La autorización debe ser previa a la contabilización de estas medidas excepcionales y tendrá una duración de 3 años desde la fecha de su concesión. El plazo para resolver el trámite es de 2 meses y se aplica el silencio administrativo positivo, en el caso de que la administración no resuelva en dicho espacio temporal.

i. La fórmula de cálculo para el cómputo anual de estas medidas alternativas es el siguiente:

1. Contratos mercantiles o civiles: IPREM (12 pagas) $\times 3$ por cada trabajador dejado de contratar. Para $2021=6.778,80 \times 3=20.336,40 €$.

2. Donación o acción de patrocinio: IPREM (12 pagas) x 1,5 por cada trabajador dejado de contratar $=6.778,80 \times 1,5=10.168,20 €$.

Para un estudio en profundidad de estas medidas excepcionales véase Pérez, 2015, pp. 419-470.

La ITSS en el ejercicio de sus funciones comprobará el cumplimiento de la cuota o de las medidas alternativas en caso de haber sido otorgada la excepcionalidad. En caso de constatación del incumplimiento legal se procederá a la iniciación de un procedimiento sancionador o, en su caso, a la advertencia o requerimiento según permite el art. 22 de la Ley 23/2015, de 21 de julio, Ordenadora del Sistema de Inspección de Trabajo y Seguridad Social.

4. El cumplimiento de la cuota de reserva, las campañas de la inspección para su cumplimiento y el impacto en el empleo del colectivo

\subsection{El cumplimiento de la cuota de reserva}

Pese a que la existencia de la obligación legal de la cuota de reserva no es nueva, sino que, al contrario, lleva décadas con nosotros desde su promulgación en 1970 por el Decreto 2531/1970 (art. 11.1), lo cierto es que su cumplimiento deja mucho que desear.

Antes de la existencia de la estadística del Instituto Nacional de Estadística (en adelante, INE) que a continuación vamos a estudiar, lo cierto es que no había manera de conocer el grado de observancia de esta exigencia normativa de reservar un porcentaje de puestos de trabajo para que sean ocupados por personas con discapacidad. Los estudios doctrinales estimaban un cumplimiento totalmente insatisfactorio que, en ningún caso superaría la mitad del objetivo de la ley, esto es, entre un 0,5 y 1\% (Mora y Cabra de Luna, 2016, pp. 84-85).

La reciente estadística publicada por el INE, de la que nos hacemos eco en el anexo 1, que recoge los datos anuales (entre 2014 a 2019) de asalariados que cotizan en empresas de más de 50 trabajadores, exceptuando centros especiales de empleo, según el porcentaje de personas con discapacidad de la empresa, nos da cierta luz sobre el grado de acatamiento de la cuota de reserva para el colectivo.

Esta estadística si bien no indica el número de empresas con 50 o más trabajadores que cumplen con la obligación legal de la cuota de reserva, señala el número de trabajadores con discapacidad que están 
empleados en empresas de este tamaño, según el porcentaje de personas con discapacidad que tiene empleadas cada organización. En la tabla se observa cómo el número de asalariados con discapacidad es cada vez menor en las empresas entre 0 y $2 \%$ de personas con discapacidad -y es mayor en la que superan esta ratio-, por lo que se concluye que se está incrementando el número de entidades que cumplen con dicha obligación legal.

En el período que hay datos (2014-2019), la reducción de trabajadores con discapacidad dados de alta en empresas de más de 50 trabajadores que tienen menos de un $2 \%$ de personas con discapacidad en sus plantillas (datos globales de empresas públicas y privadas) se ha reducido más de 20 puntos, pasando de casi un $80 \%$ a un $58 \%$. Si el dato global es extraordinariamente positivo, la cifra de reducción correspondiente al empleo público es aún mayor, un $36,2 \%$. No obstante, tenemos que tener en cuenta que este dato tendría que ser, si se cumpliera la obligación legal, un cero, por lo que el camino que queda por recorrer es aún muy largo.

Por su parte, los trabajadores dados de alta en empresas con entre un $2 \%$ y un $5 \%$ de trabajadores con discapacidad se han incrementado casi un $15 \%$ y en las empresas con más de un $5 \%$ de personas con discapacidad, el dato se ha elevado más de un $6 \%$. Por tanto, la evolución es, a todas luces, muy satisfactoria.

Sin duda, como veremos enseguida, la actuación de la ITSS para conseguir esta rebaja entendemos que ha sido, seguramente, determinante.

\subsection{Las campañas de la Inspección de Trabajo y de la Seguridad Social}

Como se observa en el anexo 2, la ITSS lleva a cabo una campaña específica de verificación del cumplimiento de la cuota de reserva de trabajadores con discapacidad. Hemos comprobado que existe alguna referencia, al menos, desde 2005, primer año del que tenemos datos en la web del organismo, pero nos hemos querido centrar en un período de diez años (2010-2019) por dos razones: por un lado, por considerar que es un tiempo prudencial para valorar una actuación pública de estas dimensiones y analizar qué impacto ha podido tener; por otro, porque coincide con el tiempo que existen datos normalizados sobre el empleo del colectivo, a través de la estadística anual que publica el INE, por lo que es posible hacer una fácil comparativa, al tener datos homogéneos con periodicidad anual.

En este punto vamos a descubrir qué información aporta la ITSS en su memoria anual y reflexionar sobre cómo se podría mejorar, si bien nos referimos únicamente a los apartados que están en todos los años de la búsqueda, indicando de entrada que sería muy deseable que los datos fuesen lo más completos posible todos los años y que no quedaran huecos vacíos como el importe de las sanciones, las medidas alternativas o las personas con discapacidad contratadas por efecto de esta campaña. En el punto siguiente uniremos la evolución del empleo del colectivo y veremos si hay algún impacto positivo de las campañas de seguimiento de la inspección en una mayor inclusión laboral de las personas con discapacidad.

Como se observa en el cuadro del anexo 2, la ITSS realiza una media de más de 3500 actuaciones anuales específicas de comprobación del cumplimiento de la cuota de reserva. Este dato supone que más de un $21 \%$ de todas las acciones relacionadas con el empleo y la contratación tienen como protagonista al colectivo de personas con discapacidad. Una primera reflexión es muy positiva. Es de recibo aplaudir el esfuerzo de la inspección para lograr el acatamiento de esta importante obligación legal prevista en la Ley General 
de derechos de las personas con discapacidad. En segundo lugar, enseguida se entiende la evolución positiva que ha quedado indicada en el punto anterior en relación con los porcentajes de cumplimiento de la cuota de reserva. Sin duda, el 'efecto llamada' o la sensación de que la ITSS está presente en el mundo empresarial y que revisa la observancia de la legislación de personas con discapacidad ha llevado a que las empresas de cincuenta o más trabajadores apuesten por cumplir la normativa.

Por otro lado, en el cuadro del anexo 2 queda reflejado que un porcentaje de aproximadamente un 6,4 \% de las actuaciones tiene aparejada una infracción, lo cual se estima exiguo para el escaso cumplimiento que hemos visto de la obligación de la cuota de reserva. Tal y como permite el ya citado artículo 22 de la Ley Ordenadora del Sistema de ITSS, finalizada la actividad comprobatoria de la Inspección, ésta podrá realizar advertencias, requerimientos o iniciar un procedimiento sancionador. Parece que los funcionarios actuantes se decantan en mayor medida por realizar varios intentos de apercibimiento o aviso, antes de imponer una sanción.

Del resto de datos que aparecen en el cuadro que estamos estudiando no tenemos una información completa, pues sólo aparecen algunos años. No obstante, en cuanto al importe medio de las sanciones, el promedio de los cinco años en los que sí tenemos cifras, sería de un poco más de $2000 €$, lo que es acorde con la calificación como infracción grave que lleva aparejada una sanción entre $626 €$ y $6250 €$ (según cuantía vigente en el momento de la imposición de la sanción). Nos parece, en todo caso, escaso el importe de las sanciones, no habiendo información de si ha habido alguna reiteración en la infracción que supondría, como antes vimos, que se impusiera en su cuantía máxima la sanción.

También sería muy interesante que todos los años se incorporara el dato del número de personas con discapacidad contratadas por efecto de las actuaciones de la ITSS. Las cantidades indicadas en los años 2014 a 2018 con casi 1950 trabajadores con discapacidad contratados de media son muy alentadores. En fin, el cómputo del importe de las medidas alternativas en ese mismo lustro que acabamos de indicar, con más de 67 millones de euros, es un dato muy relevante y compensa en gran medida la escasez de las sanciones directas impuestas a las empresas.

\subsection{El impacto en el empleo del colectivo}

Resta por analizar si estas campañas de actuación de la ITSS para la verificación del cumplimiento de la cuota de reserva que, como hemos indicado, viene siendo ejecutada desde hace al menos tres lustros, han tenido un efecto positivo en una mayor tasa de empleo del colectivo.

Como se observa en el cuadro 1 del anexo 3, las cifras de la inclusión laboral de las personas con discapacidad han ido mejorando desde 2010 hasta la actualidad, si bien entendemos que parece que han alcanzado su "techo de cristal".

Veamos con detalle los diferentes aspectos a destacar en esta estadística:

Es muy reseñable el importante aumento (+60\%) del número de personas con discapacidad en edad laboral que ha pasado de 1.171.000 personas en 2010 a 1.876.000 en 2019. Se explica porque a partir de 2014 se incorporan a dicho cómputo las personas con incapacidad laboral reconocida (ODISMET, 2020, p. 24).

a. Ello ha provocado que, a pesar de que hay más trabajadores con discapacidad, los mejores datos de tasas de ocupación, empleo y paro sean los del primer año del registro y ello quizá sea debido a una 
cuestión metodológica del propio censo y, por ello, tengamos que fijarnos más en otros datos más relevantes a los efectos de nuestro estudio.

b. El porcentaje de personas con discapacidad en la población activa se sitúa en torno al $6 \%$, un porcentaje nada desdeñable que provoca que si se quiere mejorar en algunas ratios a nivel general (tasa de actividad, tasa de empleo o mejorar la proporción de desempleo), ineludiblemente debe trabajarse el empleo de este colectivo.

c. En 2019 hay 160.000 trabajadores con discapacidad más que en 2010. Este es un dato incuestionable por el cual podemos calificar que la política de empleo está caminando en la buena dirección, sobre todo si tenemos en cuenta que buena parte de este tiempo el ciclo económico no ha acompañado. Desde 2015 se logra superar la barrera de las 400.000 personas trabajadoras con discapacidad y ya no se ha bajado de ese listón. No obstante, se observa cómo en los últimos cinco años la mejora parece haber llegado a su techo, pues el ritmo de incorporación está aminorando e incluso en el último año (2019) se ha reducido. Este escenario es previo a la crisis del COVID-19 por lo que es fácil colegir que la inclusión laboral del colectivo, como decimos, parece haber alcanzado su tope.

d. Sigue preocupando sobremanera la baja tasa de actividad de este grupo de población (34\%), más de 40 puntos porcentuales inferior al nivel general, pues ésta se sitúa en el 77,70\% según se observa en el cuadro 2 del anexo 3. Por ello, es necesario realizar alguna acción más en este sentido como apuntamos al final del estudio.

e. La tasa de paro de las personas con discapacidad se sitúa en diez puntos porcentuales superior a la de la población general, ratio que parece no poderse sortear al mantenerse durante todo el tiempo que dura la estadística, incluso con actuaciones como la de la ITSS que se está estudiando en esta investigación, por lo que es necesario un nuevo paradigma para la inclusión laboral del colectivo que apueste por nuevas medidas o por modificar las ya existentes.

La pregunta que queda por resolver es qué efecto ha podido tener la actuación de la ITSS en la comprobación del cumplimiento de la cuota de reserva de personas con discapacidad en la buena evolución del empleo del colectivo. De los 160.000 trabajadores con discapacidad más que se encuentran trabajando en 2019, los datos del anexo 2 antes analizados nos indican que casi 10.000 personas han sido efecto directo del resultado de la labor inspectora. Hay que tener en cuenta, además, que ese dato es sólo de cinco de los diez años analizados, ya que las memorias de la ITSS no muestran todos los años el dato de la contratación de personas con discapacidad resultado de las actuaciones inspectoras. A ello debemos añadir que los 67 millones de euros en medidas alternativas seguro que han sido una inyección extraordinaria para lograr un importante número de contrataciones de personas con discapacidad. Por consiguiente, podemos concluir que la cifra de empleos logrados por la actuación la ITSS en el período estudiado, tanto por contratación directa de las empresas inspeccionadas como por efecto de las medidas alternativas, es muy relevante y, sin duda, ha sido uno de los puntales para lograr el incremento de trabajadores con discapacidad. 


\section{Conclusiones. Otras medidas de apoyo al empleo del colectivo son precisas}

Los datos aportados en este trabajo muestran cómo la labor de la ITSS en el control del cumplimiento de la cuota de reserva ha sido efectiva para mejorar tanto la mejora de su observancia -un mayor número de empresas están cumpliendo con el famoso $2 \%$-, como el incremento de las personas con discapacidad que alcanzan un trabajo.

Ahora bien, se observa que la tendencia de mejora se está ralentizando o, incluso, decreciendo por lo que podemos decir que se ha llegado al "techo de cristal" en la inclusión laboral del colectivo.

Los datos aportados en las memorias de la Inspección son mejorables. Sería conveniente incluir algunas cifras que sí se han aportado unos años, pero no en otros (por ejemplo, cuantía de las sanciones, personas con discapacidad contratas por efecto de las actuaciones de control de la cuota de reserva, medidas alternativas, etc.).

Además de estas estadísticas sería muy conveniente aportar datos que ahora no son facilitados por la institución. Ante las preguntas específicas realizadas por los autores a la ITSS solicitando nuevos datos de cara a esta investigación, este organismo se escudó en la confidencialidad de sus actuaciones para no hacerlo. Sugerimos algunos datos con los que ampliar la información, tales como:

- $\quad \mathrm{n}^{\circ}$ de denuncias (disgregadas por tipología) relativas a discriminación relacionada con la discapacidad (y $\mathrm{n}^{\circ}$ de correctivos impuestos);

- $\quad \mathrm{n}^{\circ}$ de sanciones sobre acoso relacionado con esta misma temática;

- $\quad n^{\circ}$ empresas que reinciden en el incumplimiento de la cuota de reserva;

- infracciones y sanciones por aplicación incorrecta de las bonificaciones de cuotas de subvenciones o ayudas a la inserción laboral del colectivo;

- infracciones y sanciones que sean cometidas por fundaciones y asociaciones de utilidad pública beneficiarias de donaciones y acciones de patrocinio para el desarrollo de actividades de inserción y de creación de empleo de personas con discapacidad;

- información sobre sanciones accesorias relativas a personas con discapacidad;

- $\quad y$, en fin, inspeccionar a los centros especiales de empleo, tanto sobre sus condiciones de trabajo como su funcionalidad, en especial para aquellos con ánimo de lucro.

Asimismo, además de la labor de la ITSS, parece ineludible incorporar nuevas medidas para lograr unas mayores tasas de actividad y empleo del conjunto de las personas con discapacidad y, pese a que se incrementen las personas en búsqueda de un trabajo, se pueda conseguir reducir la tasa de desempleo del colectivo. Entre ellas, podría pensarse en:

- Incrementar la cuota de reserva, o disminuir el umbral de plantilla obligadas incluyendo las empresas entre 20 y 50 trabajadores (Mora y Cabra de Luna, 2016: 80, pp. 84-85). Los datos de la estadística del anexo 1 demuestran que es posible ser rentable con un porcentaje de personas con discapacidad superior incluso al $5 \%$. 
- Se precisan planes de empleo específicos por colectivos, y un ejemplo de ello sería el reciente Real Decreto 368/2021 de acción positiva para las personas con discapacidad intelectual límite, publicado en mayo de 2021.

- Es necesario establecer y diseñar adecuadamente unas prácticas no laborales para el colectivo, con la intención de incrementar específicamente la tasa de actividad y obtener mayor confianza del mundo empresarial en las capacidades de las personas con discapacidad.

- Impulsar la formación para el empleo y mejorar, sobre todo, la estabilidad de su financiación.

- Reformular la posibilidad de compatibilidad entre trabajo y pensiones de la Seguridad Social (CERMI, 2020).

- Implementar en la empresa ordinaria, como parte de la prevención de riesgos laborales y la adaptación del puesto a la persona, los apoyos que ahora mismo se prestan en los centros especiales de empleo. Éstos son, en muchos casos, verdaderas empresas accesibles e inclusivas para el colectivo y deben trasladarse sus mejores prácticas al mundo laboral ordinario.

- Y, en fin, lograr hacer efectivas las cláusulas sociales en la contratación pública, en especial para los centros especiales de empleo de iniciativa social, una estrategia impulsada especialmente a partir de 2015 y que camina en la buena dirección.

En definitiva, sabemos que en el camino para alcanzar una mayor tasa de empleo del colectivo la labor de la ITSS es relevante, -aunque podría mejorarse- pero hay que poner en marcha otras muchas y diferentes medidas, si se quiere superar el statu quo actual. Un nuevo paradigma para el empleo de las personas con discapacidad es necesario (entendida la noción de paradigma como propone Kuhn: constituye una visión del mundo dependiente de las realidades, valores y creencias de cada época, apareciendo, así, como producto de nuestra evolución cultural y el cambio del mismo lleva consigo una crisis del sistema sobre el que el mismo se proyecta (Mercader, 2017, p. 29)). 


\section{Referencias bibliográficas}

Casas, M. E. (2007). Prólogo. En R. De Lorenzo y L. C. Pérez (Dirs.), Tratado sobre discapacidad. Thomson Reuters-Aranzadi.

Cataluña. Decreto 86/2015, de 2 de junio, sobre la aplicación de la cuota de reserva del $2 \%$ a favor de personas con discapacidad en empresas de 50 o más personas trabajadoras y de las medidas alternativas de carácter excepcional a su cumplimiento. Diario Oficial de la Generalitat de Cataluña, 4 de junio de 2015, núm. 6885, pp. 1-11.

CERMI (2020). Compatibilidad entre trabajo y pensiones de Seguridad Social. Propuesta de reforma normativa desde el sector social de la discapacidad. Cinca. https://www.cermi.es/es/colecciones/compatibilidad-entretrabajo-y-pensiones-de-seguridad-social-propuesta-de-reforma.

Dirección General de la Inspección de Trabajo y de la Seguridad Social (2016). Criterio técnico 98/2016 sobre actuaciones de la Inspección de Trabajo y de Seguridad Social en materia de cuota de reserva de cuota de reserva de puestos de trabajo para personas con discapacidad. Ministerio de Empleo y Seguridad Social. https:// www.mites.gob.es/itss/ITSS/ITSS_Descargas/Atencion_ciudadano/Criterios_tecnicos/CT_98_2016.pdf.

España. Decreto 2531/1970, de 22 de agosto, sobre empleo de trabajadores minusválidos. Boletín Oficial del Estado, 15 de septiembre de 1970, núm. 221, pp. 15156-15159.

España. Ley 13/1982, de 7 de abril, de integración social de los minusválidos. Boletín Oficial del Estado, 30 de abril de 1982, núm. 103, pp. 11106-11112.

España. Ley 66/1997, de 30 de diciembre, de Medidas Fiscales, Administrativas y del Orden Social. Boletín Oficial del Estado, 31 de diciembre de 1997, núm. 313, pp. 38517-38616.

España. Ley 23/2015, de 21 de julio, Ordenadora del Sistema de Inspección de Trabajo y Seguridad Social. Boletín Oficial del Estado, 22 de julio de 2015, núm. 174, pp. 61661-61693.

España. Real Decreto 364/2005, de 8 de abril, por el que se regula el cumplimiento alternativo con carácter excepcional de la cuota de reserva en favor de los trabajadores con discapacidad. Boletín Oficial del Estado, 20 de abril de 2005, núm. 94, pp. 13466-13469.

España. Real Decreto 368/2021, de 25 de mayo, sobre medidas de acción positiva para promover el acceso al empleo de personas con capacidad intelectual límite. Boletín Oficial del Estado, 26 de mayo de 2021, núm. 125, pp. 63831-63835.

España. Real Decreto Legislativo 1/2013, de 29 de noviembre, por el que se aprueba el Texto Refundido de la Ley General de derechos de las personas con discapacidad y de su inclusión social. Boletín Oficial del Estado, 3 de diciembre de 2013, núm. 289, pp. 95635-95673.

España. Real Decreto Legislativo 5/2000, de 4 de agosto, por el que se aprueba el Texto Refundido de la Ley de Infracciones y Sanciones del Orden Social. Boletín Oficial del Estado, 8 de agosto de 2000, núm. 189, pp. 28285-28300.

España. Real Decreto Legislativo 5/2015, de 30 de octubre, por el que se aprueba el texto refundido de la Ley del Estatuto Básico del Empleado Público. Boletín Oficial del Estado, 31 de octubre de 2015, núm. 261, pp. 103105-103159. 
España. Real Decreto 365/2005, de 8 de abril, por el que se regula el cumplimiento alternativo con carácter excepcional de la cuota de reserva en favor de los trabajadores con discapacidad, Boletín Oficial del Estado, 20 de abril de 2005, núm. 94, pp. 13466-13469.

España. Real Decreto 1276/2011, de 16 de septiembre, de adaptación normativa a la Convención Internacional sobre los derechos de las personas con discapacidad. Boletín Oficial del Estado, 17 de septiembre de 2011, núm. 224, pp. 98872-98879.

Fernández, F. J. (2017). Cuotas de reserva y ajustes razonables para trabajadores con discapacidad en el ámbito laboral ordinario. Revista Española de Derecho del Trabajo, 195, pp. 63-94.

Fundación SERES et al. (2018). Guía cuota de reserva y medidas alternativas. Fundación ONCE. https://www. fundacionseres.org/Repositorio\%20Archivos/Gu\%C3\%ADa\%20cuota\%20de\%20reserva\%20y\%20discapacidad.pdf.

García, M. Á. (2004). Veinticinco años de derechos sociales en la experiencia constitucional española. Revista de Derecho Político, 58-59, pp. 277-304.

Instituto Nacional de Estadística (2020). Estadística: asalariados que cotizan en empresas de > 50 trabajadores, exceptuando centros especiales de empleo, según el porcentaje de personas con discapacidad de la empresa. Datos 2014-2019. INE. https://www.ine.es/jaxi/Tabla.htm?path=/t22/p320/base_2015/serie//0/\&file=08016. px\&L=0.

Mercader, J. (2017). El futuro del trabajo en la era de la digitalización y la robótica. Tirant lo Blanch.

Monereo, J. L. (Coord.). (2016). Manual de Derecho Administrativo Laboral. $2^{\mathrm{a}}$ ed. Tecnos.

Mora, V. y Cabra de Luna, M. A. (2016). Hacia una nueva regulación del trabajo de las personas con discapacidad. Anales de Derecho y discapacidad, 1, pp. 69-88. http://www.fderechoydiscapacidad.es/wp-content/ uploads/2017/06/ANALES-I-2016.pdf.

Muñoz, S. (1996). Presentación. En S. Muñoz y R. De Lorenzo, Código europeo de las minusvalías (pp. XXVII-XXI). Escuela Libre Editorial.

ODISMET. Observatorio sobre Discapacidad y Mercado de Trabajo en España (2020). La situación de las personas con discapacidad en el mercado laboral. Informe general. Principales resultados. Fundación Once. https:// www.odismet.es/informes-publicaciones/informe-5-del-observatorio-sobre-discapacidad-y-mercado-de-trabajo-de-la.

Organización de las Naciones Unidas (2006). Convención sobre los Derechos de las Personas con Discapacidad. ONU. https://www.un.org/development/desa/disabilities/convention-on-the-rights-of-persons-with-disabilities. html

Pérez, J. (2012). La cuota de reserva en favor de trabajadores con discapacidad: una visión crítica de la regulación de las medidas alternativas a su cumplimiento. Revista Doctrinal Aranzadi Social, 5(4), pp. 135-166.

Pérez, J. (2015). Contratación laboral de personas con discapacidad. Incentivos y cuotas de reserva. Thomson Reuters-Lex Nova. 
ANEXO 1

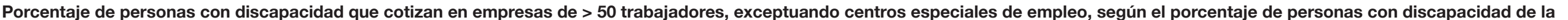
empresa

\begin{tabular}{|c|c|c|c|c|c|c|c|c|c|}
\hline \multirow[b]{2}{*}{ AÑo } & \multicolumn{3}{|c|}{ TOTALES } & \multicolumn{3}{|c|}{ SECTOR PRIVADO } & \multicolumn{3}{|c|}{ SECTOR PÚBLICO } \\
\hline & $\begin{array}{l}\text { EMPRESAS 0-2 \% } \\
\text { personas con } \\
\text { discapacidad }\end{array}$ & $\begin{array}{l}\text { EMPRESAS 2-5 \% } \\
\text { personas con } \\
\text { discapacidad }\end{array}$ & $\begin{array}{c}\text { EMPRESAS >5 \% } \\
\text { personas con } \\
\text { discapacidad }\end{array}$ & $\begin{array}{l}\text { EMPRESAS 0-2 \% } \\
\text { personas con } \\
\text { discapacidad }\end{array}$ & $\begin{array}{l}\text { EMPRESAS 2-5\% } \\
\text { personas con } \\
\text { discapacidad }\end{array}$ & $\begin{array}{c}\text { EMPRESAS >5 \% } \\
\text { personas con } \\
\text { discapacidad }\end{array}$ & $\begin{array}{l}\text { EMPRESAS 0-2 \% } \\
\text { personas con } \\
\text { discapacidad }\end{array}$ & $\begin{array}{l}\text { EMPRESAS 2-5\% } \\
\text { personas con } \\
\text { discapacidad }\end{array}$ & $\begin{array}{l}\text { EMPRESAS }>5 \% \\
\text { personas con } \\
\text { discapacidad }\end{array}$ \\
\hline 2014 & 79,4 & 13,3 & 7,3 & 74,7 & 15,8 & 9,5 & 90,7 & 7,3 & 2,1 \\
\hline 2015 & 69,9 & 19,5 & 10,7 & 68,7 & 18,4 & 12,9 & 72,8 & 22,3 & 4,8 \\
\hline 2016 & 69,1 & 20,3 & 10,6 & 67,4 & 19,3 & 13,3 & 73,8 & 22,8 & 3,3 \\
\hline 2017 & 65,1 & 22,3 & 12,5 & 64,3 & 20,7 & 15 & 67,3 & 26,7 & 6 \\
\hline 2018 & 62,7 & 24,8 & 12,5 & 61,9 & 22,6 & 15,5 & 64,7 & 30,7 & 4,7 \\
\hline 2019 & 58,5 & 28,2 & 13,4 & 60 & 26,2 & 13,8 & 54,5 & 33,4 & 12,1 \\
\hline $\begin{array}{l}\text { Evolución } \\
2014-2019\end{array}$ & $-20,9$ & 14,9 & 6,1 & $-14,7$ & 10,4 & 4,3 & $-36,2$ & 26,1 & 10 \\
\hline
\end{tabular}

Fuente: elaboración propia. Datos extraídos de INE https://www.ine.es/jaxi/Tabla.htm?path=/t22/p320/base_2015/serie/l0/\&file=08016.px\&L=0.

\section{ANEXO 2}

\begin{tabular}{|c|c|c|c|c|c|c|c|c|c|c|c|}
\hline \multicolumn{12}{|c|}{ Actuaciones de la Inspección de Trabajo y Seguridad Social (ITSS) en relación con personas con discapacidad } \\
\hline AÑo & $\begin{array}{c}\mathbf{N}^{\circ} \\
\text { ACTUACIONES } \\
\text { CUOTA DE } \\
\text { RESERVA }\end{array}$ & \begin{tabular}{|c|} 
\% SOBRE \\
TOTAL \\
ACTUACIONES \\
EMPLEOY \\
CONTRATACIÓN
\end{tabular} & REQUERIMIENTOS & INFRACCIONES & $\begin{array}{c}\% \\
\text { INFRACCIONES / } \\
\text { ACTUACIONES }\end{array}$ & $\begin{array}{l}\text { \% INFRACCIONES / } \\
\text { REQUERIMIENTOS }\end{array}$ & $\begin{array}{l}\text { \% SOBRE TOTAL } \\
\text { INFRACCIONES } \\
\text { EMPLEOY } \\
\text { CONTRATACIÓN }\end{array}$ & $\begin{array}{l}\text { IMPORTE } \\
\text { SANCIONES }\end{array}$ & $\begin{array}{l}\text { IMPORTE } \\
\text { MEDIO } \\
\text { SANCIONES }\end{array}$ & $\begin{array}{c}\text { CONTRATACIÓN } \\
\text { DE PCD } \\
\text { RESULTADO } \\
\text { DE LAS } \\
\text { ACTUACIONES }\end{array}$ & $\begin{array}{c}\text { MEDIDAS } \\
\text { ALTERNATIVAS }\end{array}$ \\
\hline 2010 & 4.381 & 24,74 & & 340 & 7,76 & & 69,39 & & & & \\
\hline 2011 & 3.099 & 17,72 & & 220 & 7,10 & & 32,4 & & & & \\
\hline 2012 & 3.501 & 19,26 & 546 & 162 & 4,63 & 29,67 & 9,93 & $387.287 €$ & $2.390,66 €$ & & \\
\hline 2013 & 3.872 & 19,79 & 698 & 276 & 7,13 & 39,54 & 8,1 & $607.297 €$ & $2.200,35 €$ & & \\
\hline 2014 & 3.343 & 16,48 & 574 & 129 & 3,86 & 22,47 & 3,67 & $254.221 €$ & $1.970,71 €$ & 1.341 & $17.321 .981 €$ \\
\hline 2015 & 3.245 & 15,44 & 797 & 177 & 5,45 & 22,21 & 3,92 & $296.488 €$ & $1.675,07 €$ & 2.092 & $8.680 .608 €$ \\
\hline 2016 & 3.593 & 24,89 & 876 & 185 & 5,15 & 21,12 & 8,99 & $392.902 €$ & $2.123,79 €$ & 4.179 & $22.041 .891 €$ \\
\hline 2017 & 3.373 & 26,02 & 708 & 144 & 4,27 & 20,34 & 9,44 & & & 1.025 & $8.301 .990 €$ \\
\hline 2018 & 3.428 & 26,1 & & 260 & 7,58 & & 12,53 & & & 1.094 & $11.398 .172 €$ \\
\hline 2019 & 3.263 & 26,39 & & 371 & 11,37 & & 21,94 & & & & \\
\hline PROMEDIO & 3.510 & 21,68 & & 226 & 6,43 & & 18,03 & & & & \\
\hline
\end{tabular}

Fuente: elaboración propia. Datos extraídos de las Memorias Anuales de la ITSS. 
ANEXO 3. Cuadro 1

Evolución del empleo de las personas con discapacidad (2010-2019)

\begin{tabular}{|c|c|c|c|c|c|c|c|c|c|c|}
\hline \multirow{2}{*}{$\begin{array}{l}\text { Personas en edad } \\
\text { laboral }\end{array}$} & \multicolumn{10}{|c|}{ El empleo de las personas con discapacidad } \\
\hline & 2010 & 2011 & 2012 & 2013 & 2014 & 2015 & 2016 & 2017 & 2018 & 2019 \\
\hline Total (en miles) & 1171,90 & 1262,00 & 1450,80 & 1428,30 & 1335,10 & 1774,80 & 1840,70 & 1860,60 & 1899,80 & 1876,90 \\
\hline $\begin{array}{l}\% \text { personas con } \\
\text { discapacidad/total }\end{array}$ & 3,80 & 4,10 & 4,69 & 4,70 & 4,40 & 5,90 & 6,10 & 6,20 & 6,30 & 6,20 \\
\hline Activos (en miles) & 423,70 & 461,60 & 531,60 & 533,60 & 506,70 & 601,10 & 647,20 & 651,70 & 654,60 & 638,60 \\
\hline Tasa de actividad (\%) & 36,00 & 36,70 & 36,70 & 37,40 & 33,60 & 33,90 & 35,20 & 35,00 & 34,50 & 34,00 \\
\hline Con empleo (en miles) & 324,98 & 337,30 & 355,50 & 346,60 & 343,30 & 414,80 & 462,00 & 481,00 & 489,50 & 485,90 \\
\hline Tasa de ocupación (\%) & 76,70 & 73,07 & 66,87 & 64,96 & 67,75 & 69,01 & 71,38 & 73,81 & 74,78 & 76,09 \\
\hline Tasa de paro (\%) & 23,60 & 26,80 & 33,20 & 35,00 & 32,70 & 31,00 & 28,60 & 26,20 & 25,20 & 23,90 \\
\hline Tasa de empleo (\%) & 27,50 & 26,80 & 24,50 & 24,30 & 22,60 & 23,40 & 25,10 & 25,90 & 25,80 & 25,90 \\
\hline
\end{tabular}

Sombreado el mej dato de cada fila.

Fuente: elaboración propia. Instituto Nacional de Estadística. El empleo de las personas con discapacidad. Datos de 2010 a 2019. www.ine.es.

ANEXO 3. Cuadro 2

Comparativa de empleo de personas con discapacidad en relación con la población general

\begin{tabular}{|c|c|c|c|c|c|c|c|c|c|c|}
\hline \multirow{2}{*}{$\begin{array}{l}\text { Personas en edad } \\
\text { laboral }\end{array}$} & \multicolumn{5}{|c|}{ Personas con discapacidad } & \multicolumn{5}{|c|}{ Personas sin discapacidad } \\
\hline & 1986 & 1999 & 2012 & 2018 & 2019 & 1986 & 1999 & 2012 & 2018 & 2019 \\
\hline Total (en miles) & $1.147,80$ & $1.337,71$ & $1.450,80$ & $1.899,80$ & $1.876,90$ & $2.3247,20$ & $39.852,65$ & $30.924,50$ & $30.180,70$ & $30.272,58$ \\
\hline $\begin{array}{l}\% \text { personas con } \\
\text { discapacidad/total }\end{array}$ & 4,94 & 3,36 & 4,69 & 6,29 & 6,20 & & & & & \\
\hline Activos (en miles) & 236,00 & 431,84 & 531,60 & 654,60 & 638,60 & $13.228,50$ & $16.265,20$ & $23.443,70$ & $22.806,8$ & $22.164,90$ \\
\hline Tasa de actividad (\%) & 20,56 & 32,28 & 36,70 & 34,50 & 34,00 & 56,90 & 52,50 & 77,20 & 77,60 & 77,70 \\
\hline Con empleo (en miles) & 147,70 & 319,18 & 355,50 & 489,50 & 485,90 & $10.263,80$ & $13.204,00$ & $17.632,70$ & $19.327,70$ & $19.082,00$ \\
\hline Tasa de ocupación (\%) & 62,58 & 73,91 & 66,87 & 74,78 & 76,09 & 77,59 & 81,18 & 75,21 & 84,75 & 86,09 \\
\hline Tasa de paro (\%) & 37,42 & 26,09 & 33,20 & 25,20 & 23,90 & 22,41 & 18,82 & 24,70 & 15,10 & 13,90 \\
\hline Tasa de empleo (\%) & 12,87 & 23,86 & 24,50 & 25,80 & 25,90 & 44,15 & 33,13 & 58,10 & 65,90 & 66,90 \\
\hline
\end{tabular}

Fuente: Elaboración propia a partir de:

Para 1986 Consejo Económico y Social (1995). Informe sobre la situación del empleo de las personas con discapacidad y propuestas para su reactivación. CES. (p. 11).

Para 1999 Jiménez Lara, A. y Huete, A. (2002). La discapacidad en cifras. IMSERSO. (p. 125) Instituto Nacional de Estadística (1999). España en cifras. INE. (pp. 4, 18 y 19).

Para 2012 Para los datos de las personas sin discapacidad: consulta realizada en www.ine.es.

Para las personas con discapacidad: Instituto Nacional de Estadística (2014). El empleo de las personas con discapacidad. Año 2012. INE.

Para 2018 Para los datos de las personas sin discapacidad: consulta realizada en www.ine.es.

Para las personas con discapacidad: Instituto Nacional de Estadística (2019). El empleo de las personas con discapacidad. Año 2018. INE.

Para 2019 Instituto Nacional de Estadística (2020). El empleo de las personas con discapacidad. Año 2019. INE. 